\title{
Maternal Satisfaction on Delivery Service and Its Associated Factors among Mothers Who Gave Birth in Public Health Facilities of Debre Markos Town, Northwest Ethiopia
}

\author{
Kurabachew Bitew, ${ }^{1}$ Mekonnen Ayichiluhm, ${ }^{2}$ and Kedir Yimam ${ }^{3}$ \\ ${ }^{1}$ Debre Markos Municipality Office, Debre Markos, Ethiopia \\ ${ }^{2}$ GAMBY College of Medical Sciences, Bahir Dar, Ethiopia \\ ${ }^{3}$ Department of Public Health, College of Medicine and Health Science, Debre Markos University, \\ P.O. Box 269, Debre Markos, Ethiopia
}

Correspondence should be addressed to Kedir Yimam; kedirymam331@gmail.com

Received 27 May 2015; Accepted 27 July 2015

Academic Editor: Mittal Suneeta

Copyright (C) 2015 Kurabachew Bitew et al. This is an open access article distributed under the Creative Commons Attribution License, which permits unrestricted use, distribution, and reproduction in any medium, provided the original work is properly cited.

\begin{abstract}
Introduction. The existence of maternal health service does not guarantee its use by women; neither does the use of maternal health service guarantee optimal outcomes for women. The World Health Organization recommends monitoring and evaluation of maternal satisfaction to improve the quality and efficiency of health care during childbirth. Thus, this study aimed at assessing maternal satisfaction on delivery service and factors associated with it. Methods. Community based cross-sectional study was conducted in Debre Markos town from March to April 2014. Systematic random sampling technique were used to select 398 mothers who gave birth within one year. The satisfaction of mothers was measured using 19 questions which were adopted from Donabedian quality assessment framework. Binary logistic regression was fitted to identify independent predictors. Result. Among mothers, the overall satisfaction on delivery service was found to be $318(81.7 \%)$. Having plan to deliver at health institution (AOR $=3.30,95 \%$ CI: 1.38-7.9) and laboring time of less than six hours (AOR $=4.03,95 \%$ CI: $1.66-9.79)$ were positively associated with maternal satisfaction on delivery service. Those mothers who gave birth using spontaneous vaginal delivery (AOR $=0.11,95 \%$ CI: $0.023-$ 0.51 ) were inversely related to maternal satisfaction on delivery service. Conclusion. This study revealed that the overall satisfaction of mothers on delivery service was found to be suboptimal. Reasons for delivery visit, duration of labor, and mode of delivery are independent predictors of maternal satisfaction. Thus, there is a need of an intervention on the independent predictors.
\end{abstract}

\section{Introduction}

Improving maternal health is one of the eight Millennium Development Goals (MDGs) adopted by the international community in 2000. Under MDG5, countries committed to reducing maternal mortality by three quarters between 1990 and 2015 [1]. Globally, maternal mortality is unacceptably high; about 800 women die from pregnancy or child birth related complications around the world every day. Two hundred eighty-seven thousand women died during and following pregnancy and childbirth in 2010; more than half of these deaths occur in Africa. The ratio of maternal mortality in the Sub-Saharan Africa region is one of the highest, reaching 686 per 100,000 live births [2, 3]. In Ethiopia the estimated maternal mortality ratio was 676 per 100,000 live births. Maternal mortality rate among women is 1.14; it represents 30 percent of all deaths for women of age 15-49 [4].

The existence of maternal health service does not guarantee their use by women; neither does the use of maternal health service guarantee optimal out comes for women [2]. The World Health Organization promotes skilled attendance 
at every birth to reduce maternal mortality and recommends that women's satisfaction be assessed to improve the quality and effectiveness of health care [5]. Patient satisfaction is a subjective and dynamic perception of the extent to which the expected health care is received [6]. It is not important whether the patient is right or wrong, but what is important is how the patient feels [7].

Studies conducted in Dhaka, Bangladesh, and South Australia indicated that the level of maternal satisfaction on delivery care was $92.3 \%$ and $86.1 \%$, respectively $[8,9]$. However, the level of satisfaction of mothers in African countries is not enough; only $51.9 \%$ and $56 \%$ of mothers' were satisfied with delivery services in South Africa and Kenya, respectively $[10,11]$. Ethiopian studies conducted in Amhara Referral Hospitals and Assela Hospital reported $61.9 \%$ and $80.7 \%$ satisfaction of mothers on delivery services, respectively $[12,13]$.

The World Health Organization recommends monitoring and evaluation of maternal satisfaction in public health care sectors to improve the quality and efficiency of health care during pregnancy, childbirth, and puerperium [5]. Maternal caregivers also wish to determine which factors in perinatal care are important for women's satisfaction $[14,15]$. Moreover, almost all of the previous studies were hospital based which may create fear on mothers to tell the bad side of the service. Thus, this study aimed at assessing satisfaction on delivery service and its associated factors among mothers who gave delivery in public health facilities of Debre Markos town.

\section{Methods}

2.1. Study Design and Study Setting. Community based crosssectional study design was used to assess level of satisfaction on delivery service and its associated factors among mothers attending delivery room of public health institutions in Debre Markos town from March up to April 2014. The study was conducted in Debre Markos town which is located $300 \mathrm{Km}$ from the capital city of Ethiopia, Addis Ababa, and $276 \mathrm{~km}$ from the Amhara region capital, Bahir Dar. There is one referral hospital and three governmental health centers in which all are providing delivery service.

2.2. Source and Study Population. All mothers who visited public health institution in Debre Markos town for delivery service were a source population. Those who gave delivery within one year in public health institutions of Debre Markos town were included. And those who were in serious illness and are unable to hear were excluded.

\subsection{Sample Size Determination and Sampling Procedure.} The sample size for this study was determined using single population proportion formula taking the prevalence of delivering mothers satisfied with hospital delivery care service in Amhara region (61.9\%) [7]. Considering 95\% CI and $5 \%$ margin of error and $10 \%$ nonresponse rate the final sample size was found to be 398 . Systematic random sampling technique with proportional allocation of mothers who gave birth within one year in each kebele of Debre Markos town was used to select the samples of this study.
2.4. Variables of the Study. Maternal satisfaction on delivery service was the dependent variable of this study. The independent variables of this study were sociodemographic factors including age, marital status, religion, education, occupation and level of income and obstetric factors including type of delivery, health condition after delivery, ANC follow-ups, duration of labor for last delivery, fetal outcome, age at first pregnancy, duration of time after last delivery, and knowledge on ANC service.

2.5. Operational Definitions. The overall satisfaction of mothers was measured based on the answer which they give for question related to satisfaction and if their response is fairly satisfied and very satisfied for $75 \%$ of questions or more they were classified as "satisfied" and otherwise they were classified as "unsatisfied."

2.6. Data Collection. The data were collected by structured questionnaire which have three parts. The first part asks about sociodemographic information of mothers and the second part is all about obstetric factors of the mother. Finally, the satisfaction of mothers was measured using 19 questions which were adopted from Donabedian quality assessment framework [16] presented using a 5-point Likert scale ranging from "very dissatisfied" to "very satisfied." Seven fourth-year public health students as data collectors from Debre Markos University and one public health graduate as supervisor from municipal office were recruited for the data collection process. Then, the questionnaires were administered using house to house visit of seven kebeles.

2.7. Data Quality Control. The questionnaire was first prepared in English and translated to Amharic and then translated back to English in order to ensure its consistency. The data collectors and supervisor were given two days of training about the objective of the study and each component of the questionnaire and after the training was given pretest was conducted on 20 respondents from Amanuel town. Principal investigator and supervisor made on the spot checking and reviewed all the completed questionnaires to ensure completeness and consistency of the information collected and immediate action was made.

2.8. Data Processing and Analysis. Data were entered and analyzed by using SPSS version 20. Descriptive statistics was computed for the study variables. To identify factors associated with mothers' satisfaction on delivery service binary logistic regression model was fitted. Odds ratio and 95\% confidence interval were used to determine the strength of association between dependent and independent variables.

2.9. Ethical Consideration. Ethical clearance was obtained from the Ethical Review Board of Debre Markos University. Communication with the kebele administrators was made through formal letter obtained from Debre Markos University. After the purpose and objective of the study were informed, verbal consent was obtained from each study participant. Participants were also informed that participation will be on voluntary basis and they can withdraw from the 
study at any time. Confidentiality of information provided by study subjects was also protected by making the data collection procedure anonymous.

\section{Result}

3.1. Sociodemographic Characteristics of Mothers. The survey included 398 mothers, of these 9 (2.61\%) were not found at home on three consecutive visits and registered as nonresponse. Among respondents, 182 (46.8\%) of them belonged to the age group of $26-35$, followed by $15-25$ age groups accounting for 167 (42.9\%) of respondents, and the remaining $40(10.3 \%)$ of them belonged to the age group of $36-45$. The mean $( \pm \mathrm{SD})$ age of the respondents was $27.4(5.3)$ years; the minimum age was 18 years and the maximum age was 43 years. The majority of the respondents (376 (96.7\%)) were followers of orthodox Christianity and the remaining were Muslims (13 (3.3\%)) (Table 1).

Regarding educational status of mothers, 108 (27.8\%) of them were at high school or preparatory level (9-12 grades) and $98(25.2 \%)$ of them were at primary school level. About $371(95.4 \%)$ of mothers were married and the remaining 18 (4.6\%) of them were single or divorced. One hundred eightysix $(47.8 \%)$ of them were housewives in occupational status and $148(38 \%)$ of them reported average monthly household income of less than 999 Ethiopian Birr (Table 1).

3.2. Obstetric Characteristics of Mothers. About 322 (82.8\%) of mothers reported that their first pregnancy was conceived at 15-25 years of age. Three hundred fifty-five (91.3\%) of pregnancies were wanted and 378 (79.4) of mothers had at least one ANC visit for the current pregnancy. The majority (363 $(93.3 \%))$ of mothers reported that they had plan to deliver at health institutions and the remaining $26(6.7 \%)$ of them were delivered in the health institutions because of difficulty to deliver at home. Among mothers, 265 (68.6\%) of them have reported that the labor stayed for less than 6 hours and assisted vaginal delivery was the mode of delivery for $189(48.6 \%)$ of them. Health complication after delivery was experienced by $364(93.6 \%)$ of mothers and the fetal outcome of almost all 388 (99\%) pregnancies was live birth (Table 2).

3.3. Maternal Satisfaction on Delivery Service. Among mothers, more than $95 \%$ of mothers were satisfied with the helpfulness of staff and health facility waiting time to be seen by health workers. And less than $85 \%$ of mothers were satisfied by accessibility of transportation and accessibility and cleanliness of toilet. Regarding their interaction with staff, more than $95 \%$ of reported that they were satisfied with use of delivery position of their choice and communication among health care providers. However, $73 \%$ and $57 \%$ of mothers were satisfied with explanation of health providers about the drugs prescribed and their side effects, respectively. About $98 \%$ and $87 \%$ of respondents were satisfied with assurance of privacy and respecting of social norms and privacy, respectively (Table 3). Among 398 mothers who gave birth within one year, the overall satisfaction of them on delivery service was found to be 318 (81.7\%) (Figure 1).
TABLE 1: Sociodemographic characteristics of mothers who gave birth within one year in Debre Markos town, Northwest Ethiopia, 2014.

\begin{tabular}{|c|c|c|}
\hline Variables & Frequency & Percentage (\%) \\
\hline \multicolumn{3}{|l|}{ Age } \\
\hline $18-25$ & 167 & 42.9 \\
\hline $26-35$ & 182 & 46.8 \\
\hline $36-45$ & 40 & 10.3 \\
\hline \multicolumn{3}{|l|}{ Religion } \\
\hline Orthodox Christian & 376 & 96.7 \\
\hline Muslim & 13 & 3.3 \\
\hline \multicolumn{3}{|l|}{ Educational status } \\
\hline Unable to read and write & 60 & 15.4 \\
\hline Able to read and write only & 29 & 7.5 \\
\hline Primary school (1-8th) & 98 & 25.2 \\
\hline High school or preparatory (9-12th) & 108 & 27.8 \\
\hline Certificate and above & 94 & 24.2 \\
\hline \multicolumn{3}{|l|}{ Marital status } \\
\hline Married & 371 & 95.4 \\
\hline Single & 10 & 2.6 \\
\hline Divorced & 8 & 2.1 \\
\hline \multicolumn{3}{|l|}{ Occupational status } \\
\hline Housewife & 186 & 47.8 \\
\hline Merchant & 92 & 23.7 \\
\hline Government employee & 57 & 14.7 \\
\hline Nongovernment employer & 20 & 5.1 \\
\hline Daily laborer & 18 & 4.6 \\
\hline Student & 16 & 4.1 \\
\hline \multicolumn{3}{|l|}{ Average household monthly income } \\
\hline$>999$ & 148 & 38 \\
\hline 999-1399 & 83 & 21.3 \\
\hline $1400-1999$ & 44 & 11.3 \\
\hline $2000-2599$ & 45 & 11.6 \\
\hline $2600-3399$ & 41 & 10.5 \\
\hline$\geq 3400$ & 28 & 7.2 \\
\hline
\end{tabular}

3.4. Factors Associated with Maternal Satisfaction on Delivery Service. In multivariate analysis, having plan to deliver at health institution ( $\mathrm{AOR}=3.30,95 \% \mathrm{CI}: 1.38-7.9)$ and laboring time of less than six hours $(\mathrm{AOR}=4.03,95 \% \mathrm{CI}$ : 1.66-9.79) were significantly and positively associated with maternal satisfaction on delivery service. The likelihood of maternal satisfaction on delivery service was lower $(\mathrm{AOR}=$ 0.11, 95\% CI: 0.023-0.51) among mothers who experienced spontaneous vaginal delivery as compared to mothers who experienced cesarean section (Table 4).

\section{Discussion}

In this study, the overall satisfaction of mothers on delivery service was found to be $81.7 \%$ which was in line with 
TABLE 2: Obstetrics characteristics among mothers who gave birth within one year in Debre Markos town, Northwest Ethiopia, 2014.

\begin{tabular}{|c|c|c|}
\hline Variables & Frequency & Percentage (\%) \\
\hline \multicolumn{3}{|l|}{ Age at first pregnancy } \\
\hline $15-25$ & 322 & 82.8 \\
\hline $26-35$ & 67 & 17.2 \\
\hline \multicolumn{3}{|l|}{ Parity } \\
\hline Two & 182 & 46.8 \\
\hline Three & 165 & 42.4 \\
\hline Four or more & 42 & 10.8 \\
\hline \multicolumn{3}{|l|}{ Wanted status of pregnancy } \\
\hline Yes & 355 & 91.3 \\
\hline No & 34 & 8.7 \\
\hline \multicolumn{3}{|l|}{ Number of ANC visits } \\
\hline One & 378 & 79.4 \\
\hline Two & 60 & 15.4 \\
\hline Three & 11 & 2.8 \\
\hline Four & 9 & 2.3 \\
\hline \multicolumn{3}{|l|}{ Reason for visit } \\
\hline Planned & 363 & 93.3 \\
\hline Referral & 26 & 6.7 \\
\hline \multicolumn{3}{|l|}{ Duration of labor } \\
\hline$<6$ hours & 265 & 68.1 \\
\hline $6-12$ hours & 91 & 31.5 \\
\hline 12-24 hours & 17 & 4.3 \\
\hline Above 24 hours & 16 & 4.1 \\
\hline \multicolumn{3}{|l|}{ Type of delivery } \\
\hline Assisted delivery & 189 & 48.6 \\
\hline Spontaneous vaginal delivery & 168 & 43.2 \\
\hline Cesarean section & 32 & 8.2 \\
\hline \multicolumn{3}{|l|}{ Condition of mother after delivery } \\
\hline Without complication & 364 & 93.6 \\
\hline With complication & 25 & 6.4 \\
\hline \multicolumn{3}{|l|}{ Outcome of pregnancy } \\
\hline Lived & 385 & 99 \\
\hline Died & 4 & 1.0 \\
\hline \multicolumn{3}{|l|}{ Time passed after delivery } \\
\hline$\leq 6$ months & 212 & 54.5 \\
\hline$>6$ months & 177 & 45.5 \\
\hline
\end{tabular}

the study conducted in Wolayita Zone (82.9\%), Jimma (77\%), and Assela Hospital (80.7\%) [9, 12, 17]. However, this finding was higher $(61.9 \%)$ than the study which was conducted in Amhara Referral Hospitals. The difference with the above finding could be explained by a real difference in the quality of services provided (as Debre Markos Referral Hospital received national quality award by $\mathrm{MOH}$ in 2014), expectation of mothers, or the type of health facilities [13]. In addition, two of the three referral hospitals selected in Amhara region study were teaching based which may increase their dissatisfaction due to reasons such as repeated vaginal examination and absence of privacy.

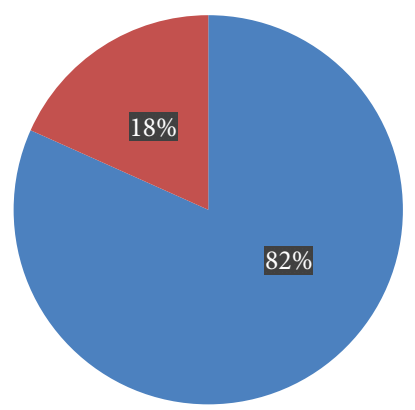

$$
\begin{aligned}
& \text { - Satisfied } \\
& \text { - Not satisfied }
\end{aligned}
$$

Figure 1: Prevalence of maternal satisfaction on delivery service among mothers who gave birth within one year in Debre Markos town, Northwest Ethiopia, 2015.

Having plan to deliver at health facility was significantly and positively associated with maternal satisfaction on delivery services. This finding was similar with the study conducted in Assela Hospital and other foreign literatures. The literatures showed that clients had various expectations about hospital delivery that influenced their perception of care. These expectations were based on their own past experiences in a hospital facility, experiences of friends and relations in a hospital facility, myths about procedures in the hospital and societal values, and perception of an assisted delivery $[12,18]$.

In this study, laboring time of mothers was significantly associated with satisfaction of mothers on delivery services. Similarly, a study conducted in Wolayita Zone showed that the satisfaction of mothers who stayed on labor pain for less than a sunset was higher. One study in North Gondar Zone also indicated that suffering with complication and having long labor influence the satisfaction of mothers on health institution delivery service $[19,20]$. A randomized controlled trial of active management of labor conducted in Auckland, New Zealand, reported that the practice was related to reduction of labor time and a postpartum report of longer labor than expected was strongly associated with reduction of maternal satisfaction $[21,22]$.

This study demonstrated that spontaneous vaginal delivery was significantly associated with reduction of satisfaction on delivery care. This finding was unexpected and not in line with report of other similar studies [23, 24]. Several other studies also failed to detect difference in level of maternal satisfaction among those who have different mode of delivery $[13,22]$. As in Ethiopia most of cesarean section deliveries were conducted at emergency situation, saving their baby in that situation may change their perception towards the facility which might be the possible explanation for the finding.

Absence of inferring causality due to cross-sectional nature of the study and the presence of recall bias due to long time lapse after childbirth are among the limitations of this study. Regarding the strengths of this study, community based nature of this study also minimizes social desirability bias. 
TABLE 3: Satisfaction on health facility and staff related variables among mothers who gave birth in public facilities of Debre Markos town, Northwest Ethiopia, 2014.

\begin{tabular}{|c|c|c|c|}
\hline \multirow{2}{*}{ Domains } & \multirow{2}{*}{ Variables } & \multicolumn{2}{|c|}{ Satisfaction } \\
\hline & & Yes, $n(\%)$ & No, $n(\%)$ \\
\hline \multirow{7}{*}{ Physical and staff accessibility } & Examination area cleanliness and comfort & $373(95.9)$ & $16(4.1 \%)$ \\
\hline & Restfulness of the rooms of the facility & $360(92.5)$ & $29(7.5)$ \\
\hline & Overall cleanness of the facility & $345(88.7)$ & $44(11.3)$ \\
\hline & Availability of transportation & $326(83.8)$ & $63(16.2)$ \\
\hline & Supplies of basic drugs and equipment & $349(89.7)$ & $40(10.3)$ \\
\hline & Accessibility and cleanness of toilets and/or shower & $324(83.3)$ & $65(16.7)$ \\
\hline & Waiting time to be seen by health worker & $372(95.6)$ & $17(4.4)$ \\
\hline \multirow{9}{*}{$\begin{array}{l}\text { Interaction with providers and } \\
\text { staff of the facility }\end{array}$} & Helpfulness of staff & $377(96.9)$ & $12(3.1)$ \\
\hline & Explanation about the treatment given & $359(92.3)$ & $30(7.7)$ \\
\hline & Communication between health care providers & $383(98.5)$ & $6(1.5)$ \\
\hline & Opportunity to ask about the treatment & $343(88.2)$ & $46(11.8)$ \\
\hline & Involvement of patient in decision making & $305(78.4)$ & $85(21.6)$ \\
\hline & Willingness of staff to hear patient problems & $368(94.6)$ & $21(5.4)$ \\
\hline & Explanation about the drugs prescribed & $284(73)$ & $105(27)$ \\
\hline & Explanation about the side effects of drugs & $222(57.1)$ & $167(42.9)$ \\
\hline & Delivery position of patient choice & $372(95.6)$ & $14(4.4)$ \\
\hline \multirow{3}{*}{$\begin{array}{l}\text { Provision of respect and } \\
\text { privacy }\end{array}$} & Respect and assurance of privacy & $380(97.7)$ & $9(2.3)$ \\
\hline & Respect of social norms and values & $329(84.6)$ & $60(15.4)$ \\
\hline & Equal treatment of people & $339(87.1)$ & $50(12.9)$ \\
\hline
\end{tabular}

TABLE 4: Factors associated with maternal satisfaction on delivery service among those who gave birth within one year in Debre Markos town, Northwest Ethiopia, 2014.

\begin{tabular}{|c|c|c|c|c|}
\hline \multirow{2}{*}{ Variables } & \multicolumn{2}{|c|}{ Maternal satisfaction } & \multirow{2}{*}{ Crude OR (95\% CI) } & \multirow{2}{*}{ Adjusted OR (95\% CI) } \\
\hline & Satisfied & Unsatisfied & & \\
\hline \multicolumn{5}{|l|}{ Reason for delivery visit } \\
\hline Planned & $302(83.2 \%)$ & $61(16.8 \%)$ & $3.09(1.34-7.143)$ & $3.30(1.38-97.9)^{* *}$ \\
\hline Referred & $16(61.5 \%)$ & $10(38.5 \%)$ & 1 & 1 \\
\hline \multicolumn{5}{|l|}{ Laboring time } \\
\hline$<6$ hours & $227(85.7 \%)$ & $38(14.3 \%)$ & $2.60(1.15-5.89)$ & $4.03(1.66-9.79)^{* *}$ \\
\hline 6-12 hours & $68(74.7 \%)$ & $23(25.3 \%)$ & $1.29(0.53-3.10)$ & $1.45(0.57-3.68)$ \\
\hline Above 12 hours & $23(69.7 \%)$ & $10(30.3 \%)$ & 1 & 1 \\
\hline \multicolumn{5}{|l|}{ Mode of delivery } \\
\hline Spontaneous vaginal & $127(75.6 \%)$ & $41(24.4 \%)$ & $0.21(0.05-0.90)$ & $0.11(0.023-0.51)^{* *}$ \\
\hline Assisted delivery & $161(85.2 \%)$ & $28(14.8 \%)$ & $0.38(0.09-1.70)$ & $0.27(0.06-1.24)$ \\
\hline Cesarean section & $30(93.75)$ & $2(6.25 \%)$ & 1 & 1 \\
\hline
\end{tabular}

\section{Conclusion}

This study revealed that the overall satisfaction of mothers on delivery service was found to be suboptimal. However, there is still much work needed in the domain of interaction of mothers with health care providers. Reasons for delivery visit, duration of labor, and mode of delivery are independent predictors of maternal satisfaction. Thus, there is a need of an intervention on the independent predictors.

\section{Conflict of Interests}

The authors declared that there is no conflict of interests.

\section{Acknowledgments}

The authors would like to thank all their friends who contributed their endless effort for the successful accomplishment of this work. They would like to thank all supervisors 
and data collectors for their unreserved commitment and timely submission. They would like to thank also Debre Markos health posts and their staff for their support by giving the number of mothers' who deliver in public health institution within one year in all kebeles in Debre Markos town.

\section{References}

[1] World Health Organization, Trends in Maternal Mortality: 1990 to 2013 Estimates, WHO, UNICEF, UNFPA, The World Bank and United Nations Population Division Maternal Mortality, Geneva, Switzerland, 2013.

[2] World Health Organization, World Health Statistics 2013; A Wealth of Information on Global Health, World Health Organization, Geneva, Switzerland, 2013.

[3] WHO, UNICEF, UNFPA, and WORLD BANK, Maternal Mortality in 2005; Estimates Developed by WHO, UNICEF, UNFPA and the World Bank, WHO, Geneva, Switzerland, 2007.

[4] Central Statistical Agency and ICF Macro, Ethiopia Demographic and Health Survey, ICF Macro, Calverton, Md, USA, 2011.

[5] World Health Organization (WHO), Making Pregnancy Safer: The Critical Role of the Skilled Attendant: A Joint Statement by WHO, ICM, FIGO, World Health Organization (WHO), Geneva, Switzerland, 2004.

[6] J. H. Larrabee and L. V. Bolden, "Defining patient-perceived quality of nursing care," Journal of Nursing Care Quality, vol. 16, no. 1, pp. 34-60, 2001.

[7] D. E. Jatulis, N. I. Bundek, and A. P. Legorreta, "Identifying predictors of satisfaction with access to medical care and quality of care," American Journal of Medical Quality, vol. 12, no. 1, pp. 11-17, 1997.

[8] A. Hasan, J. Chompikul, and S. U. Bhuiyan, Patient Satisfaction with Maternal and Child Health Service among Mothers Attending the Maternal and Child Health Training in Dahaka Bangeladish, Mahidol University, 2007.

[9] Australian Government, Maternity Service in South Australia Public Hospital: Patient Satisfaction Survey Research, Australian Government, South Australia, Australia, 2007.

[10] T. G. Lumadi and E. Buch, "Patients' satisfaction with midwifery services in a regional hospital and its referring clinics in the Limpopo Province of South Africa," Africa Journal of Nursing and Midwifery, vol. 13, no. 2, pp. 14-28, 2011.

[11] E. S. Bazant and M. A. Koenig, "Women's satisfaction with delivery care in Nairobi's informal settlements," International Journal for Quality in Health Care, vol. 21, no. 2, pp. 79-86, 2009.

[12] R. Amdemichael and M. Tafa, "Maternal satisfaction with the delivery services in Assela Hospital, Arsi zone, Oromia region," Gynecology \& Obstetrics, vol. 4, article 257, 2014.

[13] A. Tayelgn, D. T. Zegeye, and Y. Kebede, "Mothers' satisfaction with referral hospital delivery service in Amhara Region, Ethiopia," BMC Pregnancy and Childbirth, vol. 11, article 78, 2011.

[14] S. Brown and J. Lumley, "Changing childbirth: lessons from an Australian survey of 1336 women," British Journal of Obstetrics and Gynaecology, vol. 105, no. 2, pp. 143-155, 1998.

[15] S. Brown and J. Lumley, "Satisfaction with care in labor and birth: a survey of 790 Australian women," Birth, vol. 21, no. 1, pp. 4-13, 1994.
[16] A. Donabedian, An Introduction to Quality Assurance in Health Care, Oxford University Press, New York, NY, USA, 2002.

[17] F. Assefa, A. Mosse, and Y. H/Michael, "Assessment of clients' satisfaction with health service deliveries at Jimma university specialized hospital," Ethiopian Journal of Health Sciences, vol. 21, no. 2, 2011.

[18] P. A. Field, "Client care seeking behaviors and sources of satisfaction with nursing care," Nursing Papers, vol. 14, no. 1, pp. $15-28,1987$.

[19] B. Yohannes, M. Tarekegn, and W. Paulos, "Mothers' utilization of antenatal care and their satisfaction with delivery services in selected public health facilities of Wolaita Zone, Southern Ethiopia," International Journal of Scientific \& Technology Research, vol. 2, no. 2, 2013.

[20] S. Bipna, B. Dhimal, S. Nironjan, and D. Bikram, "Client's satisfaction on maternity services at Paropakar maternity and women's hospital, Kathmandu," Journal of Health and Allied Sciences, vol. 1, no. 1, pp. 56-59, 2010.

[21] C. Lynn, D. Tracey, and M. E. M. Lesley, "A randomized controlled trial and meta-analysis of active management of labor," British Journal of Obstetrics and Gynaecology, vol. 107, no. 7, pp. 909-915, 2000.

[22] L. C. Sadler, T. Davison, and L. M. E. McCowan, "Maternal satisfaction with active management of labor: a randomized controlled trial," Birth, vol. 28, no. 4, pp. 225-235, 2001.

[23] B. Matejić, M. T. Milićević, V. Vasić, and B. Djikanović, "Maternal satisfaction with organized perinatal care in Serbian public hospitals," BMC Pregnancy and Childbirth, vol. 14, no. 1, article 14, 2014.

[24] M. V. Dzomeku, "Maternal satisfaction with care during labor: a case study of the Mampong-Ashanti district hospital maternity unit in Ghana," International Journal of Nursing and Midwifery, vol. 3, no. 3, pp. 30-34, 2011. 


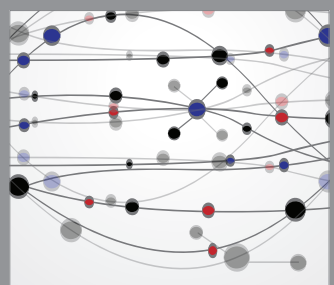

The Scientific World Journal
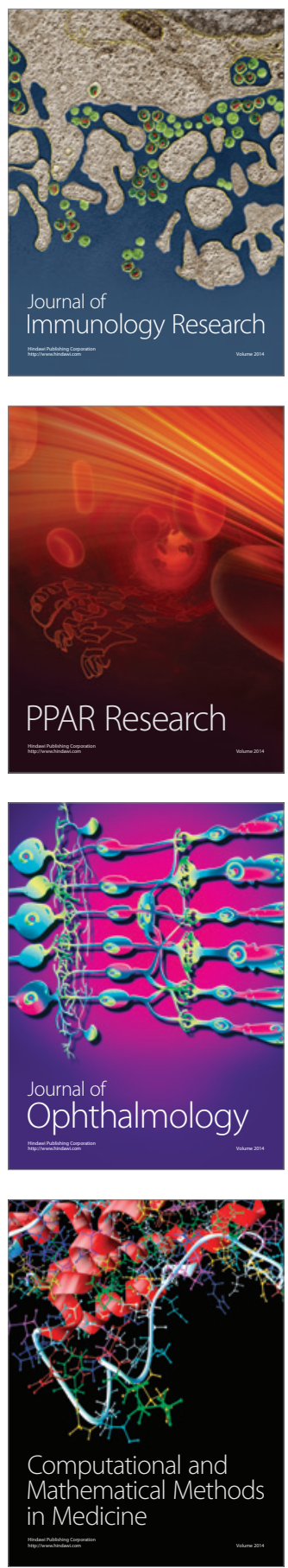

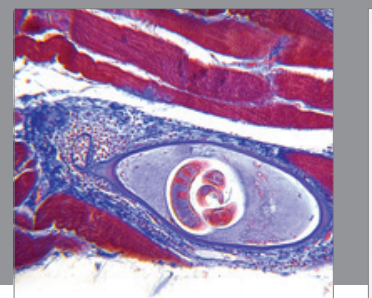

Gastroenterology

Research and Practice
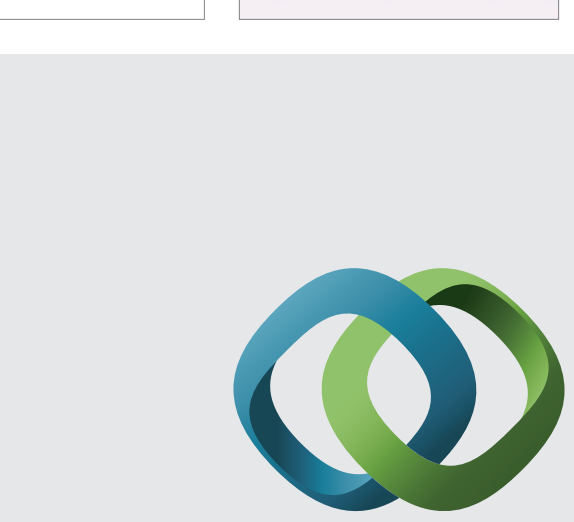

\section{Hindawi}

Submit your manuscripts at

http://www.hindawi.com
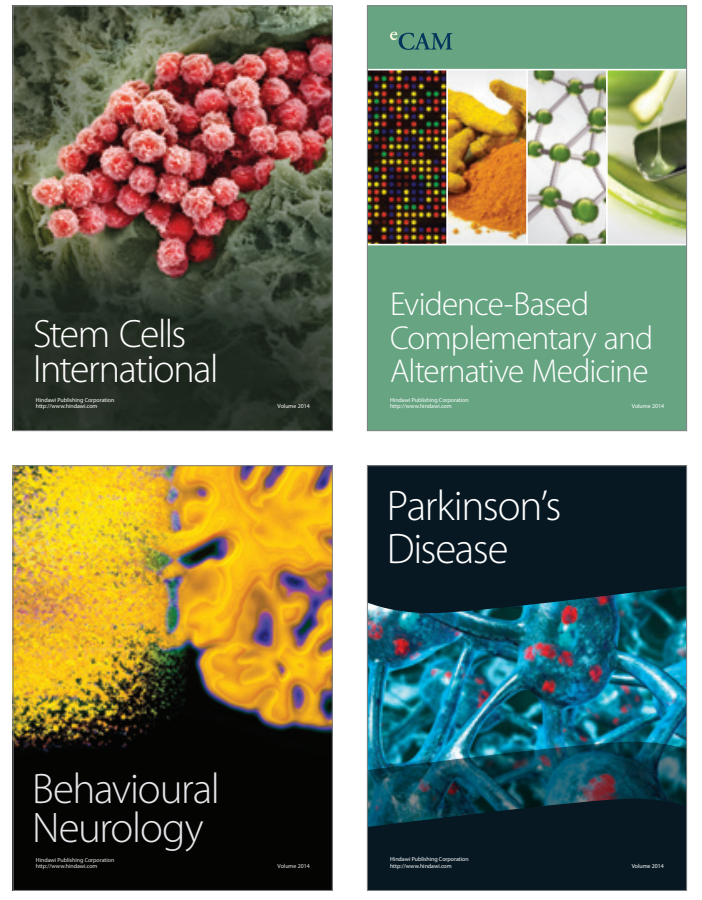
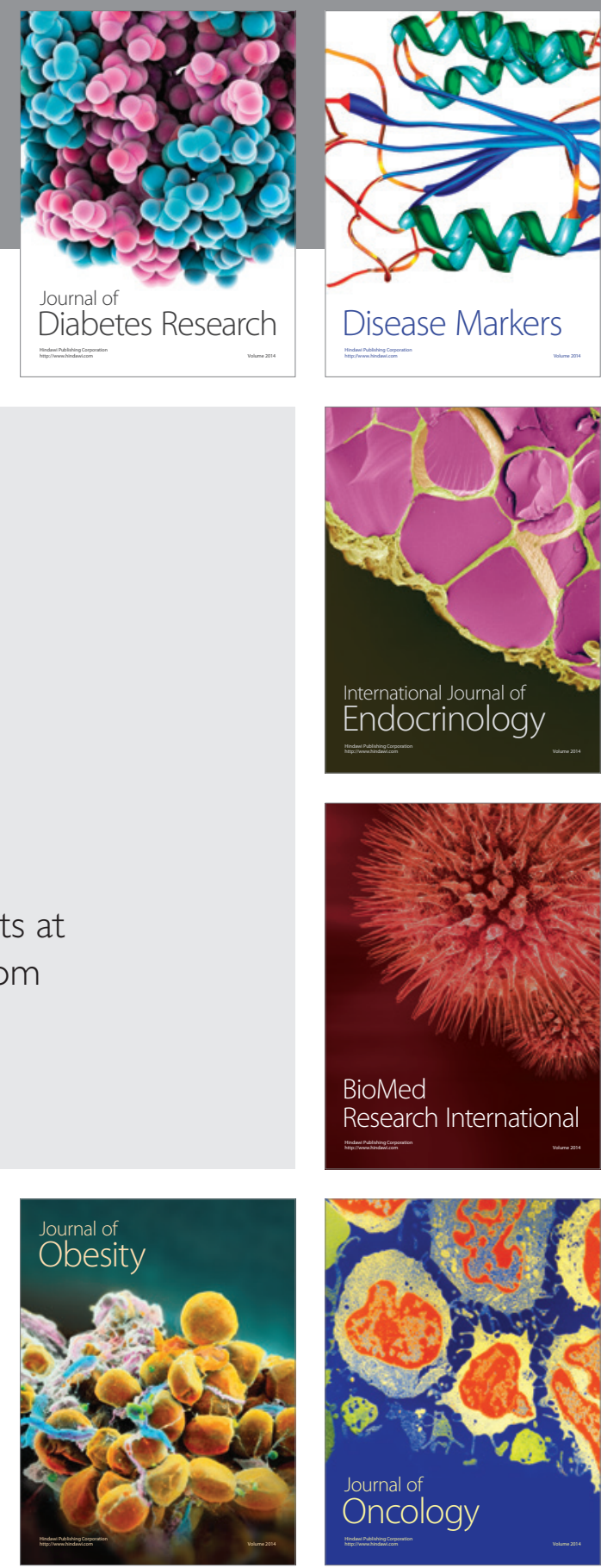

Disease Markers
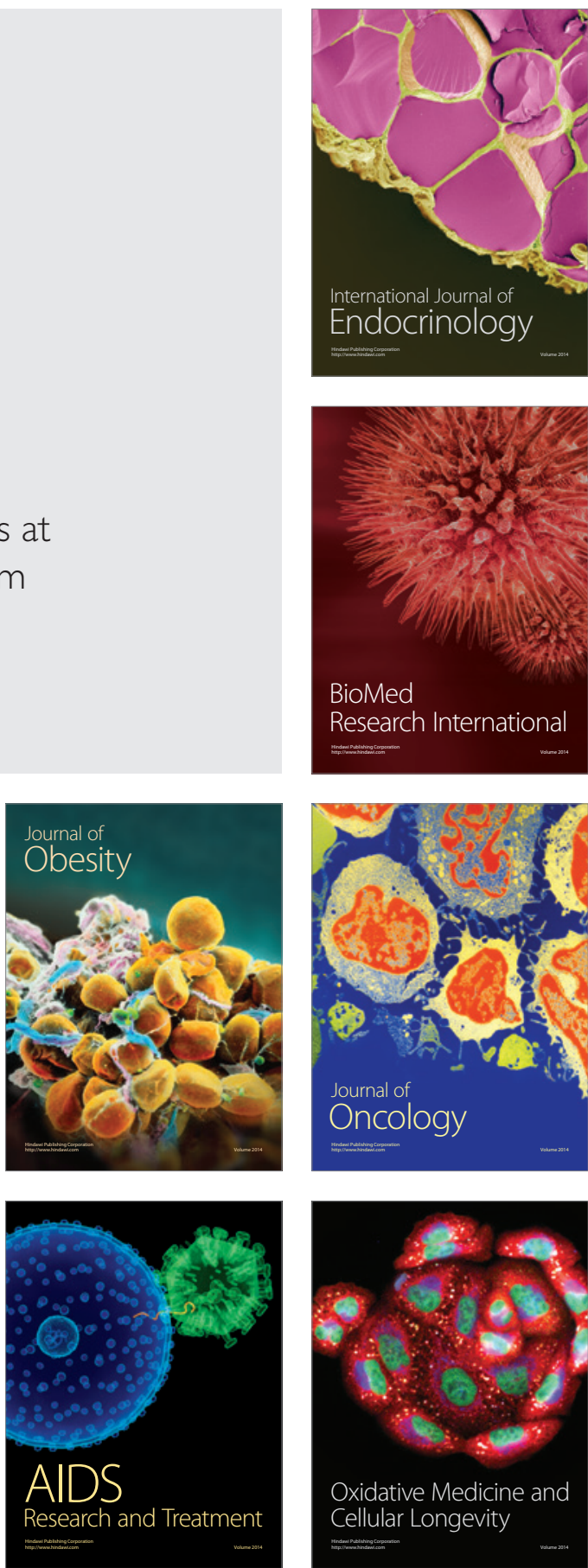